\title{
ERUPTIVE SYRINGOMAS IN ASSOCIATION WITH SEVERE PERIODONTAL DISEASE
}

\author{
Sonya Márina, Valentina Broshtilova, Jana Kazandjieva, Dimitrina Guleva \\ Department of Dermatology and Venereology, Medical University - Sofia, Bulgaria
}

\begin{abstract}
Generalized eruptive syringomas are a rare clinical presentation of a benign adnexal tumor derived from the intraepidermal portion of the eccrine sweat ducts. Clinical presentation shows asymptomatic flesh-colored tumors on the anterior part of the trunk. A case of a 51-year-old male with a long-standing generalized eruption of multiple brown-colored papules, accompanied by odorous perspiration and total loss of teeth, which appeared suddenly three years ago. A punch biopsy specimen revealed a normal epidermis overlying a dermis that was covered with multiple ducts embedded in a fibrous stroma. The diagnosis of multiple syringomas was drawn. The perspiration odor was attributed to the presence of Gram-negative anaerobic bacteria. Speculations on the possible common pathogenetic background are presented.
\end{abstract}

Keywords: multiple syringomas, perspiration, periodontal disease

\section{INTRODUCTION}

Syringomas are benign adnexal tumors of eccrine origin, with four principal clinical variants (1). Jacquet and Darier were the first to describe a generalized distribution of the tumors on the anterior part of the chest, neck, upper abdomen, axillae and periumbilical region (2). The lesions consist of asymptomatic, multiple, firm yellow-brown-colored papules, typically present in a bilateral symmetric distribution. Wider involvement of the body has also been described (3). Unilateral nevoid, and bathing trunk distribution have rarely been seen (4). The lesions may resolve spontaneously, however, it is more

Address for correspondence:

Dimitrina Guleva

Department of Dermatology and Venereology

Medical University of Sofia, Bulgaria

1 „Sv. G. Sofiiski“Str.

1431 Sofia, Bulgaria

e-mail:dimiguleva@gmail.com

phone: +35929172580

Received: November 8, 2015

Accepted: February 2, 2016 likely than not that they stay stable or grow in number in irregular clusters. Differential diagnosis distinguishes acne vulgaris, sebaceous hyperplasia, milia, lichen planus, eruptive xanthoma, urticaria pigmentosa, hidrocystoma, trichoepithelioma and xanthelasma on the face and granuloma annular on the trunk (5). The highly characteristic histology consists of an epithelial growth in the form of tubules or nests made up of 2 flat cell layers; these structures develop a "tadpole-shaped" tail. No studies have confirmed therapeutic efficacy (6). Herein, a unique case of multiple giant syringomas in association with severe periodontal disease and odorous perspiration is presented.

\section{CASE REPORT}

A 51-year-old Caucasian man was admitted to our department with a long-standing generalized eruption of multiple brown-colored papules, associated with odorous perspiration and total loss of teeth which appeared suddenly three years ago. The patient claimed that his skin symptoms began after a smallpox infection at the age of 11 on the right side of his lower eyelids, and gradually spread to the ab- 
domen, neck, and neckline, with outbreaks after periods of sun exposure. The lesions did not resolve but spread and grew in size. There was no one in the family who was similarly affected. The patient denied any medical problems or the use of over-thecounter products. He overlooked his skin condition until three years ago when, after abrupt psycho-emotional distress, unpleasant smell during perspiration appeared. At the same time he lost all his teeth over a one-month period.

Physical examination revealed multiple, browncolored, flat-topped papules, with a various sized ranging from $5 \mathrm{~mm}$ to $3 \mathrm{~cm}$ in diameter, localized bilaterally and symmetrically on the skin of the forearm, thigh, neck, anterior chest, upper abdomen and back.

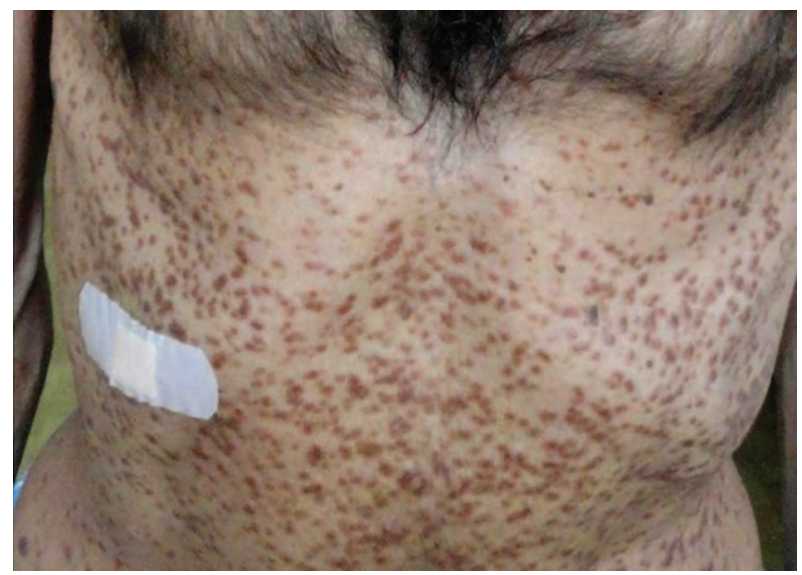

Fig.1. Multiple brown-colored, flat-topped papules on the skin of the chest and upper abdomen

The lesions were characterized by -follicular and non-follicular distribution. There was a negative Darier's sign. His oral cavity did not have any pathological lesions except for the lack of all teeth. No hyperhidrosis was present. Microbial analysis of a sweat sample showed Gram-negative rod-shaped anaerobic pathogenic bacteria of the Bacteroides phylum that formed black colonies on blood agar. The review of systems was noncontributory. A skin biopsy was obtained from a lesion in the upper abdomen. The histological examination showed a normal epidermis and a dermis filled with multiple ducts embedded in a fibrous stroma.

Flattened epithelial cells were observed in the inner layer of the ducts. Some of the ducts had a tad-



Fig. 2. Histological findings showed a normal epidermis and a dermis filled with multiple ducts embedded in a fibrous stroma

pole-like appearance formed by the one side of the duct located into the stroma. There was an amorphous material in the ductal lumina. The diagnosis of multiple syringomas was drawn. The perspiration odor was attributed to the presence of Gram-negative anaerobic bacteria.

\section{DISCUSSION}

Syringomas are uncommon neoplasms, described mainly in pre-pubertal women. They manifest as firm, rounded, pale pink or yellow-colored papules of 1-3 mm diameter (7). Syringomas have traditionally been classified according to Friedman and Butler's view in four clinical forms: localized, familial, Down syndrome-associated, and generalized (8). Generalized syringomas show two main variants: multifocal and eruptive (9). The eruptive form features many heat-induced outbreaks of papular elements in the anterior and lateral region of the neck, trunk, axillae, abdomen, genital area, and limbs, between 4 and 10 years of age.

Two interesting clinical features could be distinguished in our patient. First, he belongs to the minority of male subjects affected by the disease, and second, the lesions are larger in size, and may be classified as giant - over $1 \mathrm{~cm}$ in diameter. It can be due to the long duration of the condition; hence, it decreases the female sex hormone significance in the pathogenesis of the disease.

Histology findings are pathognomonic, showing an epithelial growth in the upper half of the retic- 
ular dermis consisting of cells with a pale eosinophilic cytoplasm arranged in nests or tubules and surrounded by a sclerotic stroma (10). The tubular areas contain basophilic granular cells and ductal differentiation with central lumens lined with a compact eosinophilic cuticle. Remarkably, the onset of the disease in our patient followed a smallpox infection, a fact that can be contributed to the hypothesis that eruptive syringomas are sequelae to a reactive hyperplasia of the sweat glands accompanying inflammatory processes (11). The histological differential diagnosis ruled out milia, microcystic adnexalcarcinoma, and desmoplastic trichoepithelioma.

Eruptive syringomas are usually asymptomatic. They are frequently associated with Down, Marfan, and Ehlers-Danlos syndromes (12). Anecdotally, syringomas present with milia and atrophoderma vermiculata in the context of Nicolau Balus syndrome (13). Reports of familial inheritance and relation to diabetes, alopecia, carcinoid tumors have also been reported $(14,15)$. Our patient has severe periodontal disease that appeared simultaneously with odorous sweating. Perhaps, both conditions are due to a profound anaerobic infection, arguments of which exist in the microbiological swabs of the patient. Interestingly, a substantially increased frequency of a periodontal disease has been found in patients with autoimmune disorders compared to healthy subjects (16). Antibodies to Gram-negative anaerobic periodontal pathogens are found in the blood and synovial fluid of many patients with rheumatoid arthritis (17). Since periodontal disease is one of the most common chronic disorders of infectious origin in humans, extreme scientific efforts have been dedicated to unveil its pathogenesis (18). To date, it is well-proven that most patients with periodontitis respond to bacterial invaders by mobilizing their defense cells and releasing cytokines such as interleukin-1 beta, interleukin-6 and tumor necrosis factor alpha (17). Thus, the production of collagenolytic enzymes is stimulated and as a consequence cell cycle progression is suppressed and apoptosis increased. Actually, periodontitis is associated with an increased risk of diabetes mellitus, atherosclerosis, and connective tissue diseases. The aggressive periodontitis in our patient is related to perspiration odor, probably, due to the increased colonization of anaerobic bacteria as a consequence of compromised skin immune reactivi- ty. This phenomenon is only a by-stander and cannot share common pathologic and immunological aspects with multiple syringomas, although sweat duct elements of the tumor could be invaded by anaerobic bacteria, a fact that we were not able to prove.

Treatment of syringoma is cosmetic. The options are abundant and generally unsatisfactory. Therapeutic modalities have included dermabrasion, various methods of excision, cryosurgery, electrodesiccation, chemical peeling and oral and topical retinoids. Because they are located in the dermis and often numerous, there is no standard treatment for widespread syringomas, as in our patient. Clarithromycin was administered as a treatment option for the anaerobic infection. Nowadays, an option for facial syringomas with very good clinical response is the carbon dioxide $\left(\mathrm{CO}_{2}\right)$ laser.

\section{CONCLUSIONS}

Our case was a 51-year old man who had lesions of generalized eruptive giant syringomas with more than a 30 -year duration. The patient presented with a three-year history of odorous sweating and total loss of teeth due to severe periodontal disease. This association is incidental, however, it contributes to the recent hypothesis of the possible pathogenetic connection between aggressive oral anaerobic infection and acquired systemic immunosuppression.

\section{REFERENCES}

1. Patrizi A, Neri I, Marzaduri S, Varotti E, Passarini W. Syringoma: a review of twenty-nine cases. Acta Derm Venereol 1998; 78: 460-2.

2. Jacquet L, Darier J. Hiydradénomes éruptifs, épithéliomes adénoides des glandes sudoripares ou adénomes sudoripares. Ann Dermatol Syph 1887; 8: 317-23.

3. Goyal S, Martins CR. Multiple syringomas on the abdomen, thighs and groin. Cutis 2000; 66: 259-62.

4. Soler-Carrilo J, Estrach T, Mascaró JM. Eruptive syringoma: 27 new cases and review of the literature. J Eur Acad Dermatol Venereol 2001; 15:242- 6.

5. Mahnaz J, Mitra H, Parvin R. Generalized eruptive syringomas. Indian J Dermatol 2009; 54:65-7.

6. Frazier CC, Camacho AP, Cockerell CJ. The treatment of eruptive syringoma in an African-American patient with a combination of trichloroace- 
tic acid and CO2 laser destruction. Dermatol Surg 2001; 27(5): 489-92.

7. Fernández-Crehuet P, Herrera-Saval A, Domínguez-Cruz J, Camacho FM. Generalized Syringoma: A Case Study. Actas Dermosifiliogr 2007; 98(8): 575-6.

8. Friedman SJ, Butler DF. Syringoma presenting as milia.J Am Acad Dermatol 1987;16:310-4

9. Janninger CK, Brodkin RH. Eruptive syringomas. Cutis 1990; 46: 427-9.

10. Ambrojo P, Requena Caballero L, Aguilar Martinez A, Sánchez Yus E, Furió V. Clear-cell syringoma: Immunohistochemistry and electron microscopy study. Dermatologica 1989; 178:164-6.

11. Guitart J, Rosenbaum M, Requena L. Eruptive syringoma: a misnomer for a reactive eccrine gland ductal proliferation? J Cutan Pathol 2003; 30(3): 202-5.

12. Draznin M. Hereditary syningomas: A case report. Dermatol Online J 2004; 10(2):19.

13. Berbis P, Fabre JF, Jancovici E, Privat Y. Benderitter T. Late-onset syringomas of the upper extremities associated with a carcinoidtumor. Arch Dermatol 1989; 125(6): 848-9.

14. Metze D, Wigbels B, Hildebrand A. Familial syringoma: A rare clinical variant. Hautarzt. 2001; 52(11): 1045-8.

15. Creamer D, Macdonald A, Briffiths WA. Unilateral linear syringomata. A case report. Clin Exp Dermatol 1999; 24(5): 428-30.

16. Al-Katma M, Bissada N, Bordeaux J, Sue J, Askari AD. Control of periodontal infection reduces the severity of active rheumatoid arthritis. J Clin Rheumatol 2007; 13(3): 134-7.

17. Ogrendik M. Does periodontopathic bacterial infection contribute to the ethiopathogenesis of the autoimmune diasease rheumatoid arthritis? Discov Med 2012; 13(72): 349-55.

18. Stein J, Said Yekta S, Kleines M, OkD, Kasaj A, Reichert S, Schulz S, Scheithauer S. Failure to detect an association between aggressive periodontitis and the prevalence of herpesviruses. J Clin Periodontol 2013; 40(1): 1-7. 